\title{
Community-acquired Pneumonia Associated with Ulcerative Stomatitis and Vesiculobullous Lesions
}

\author{
Toplum Kaynaklı Pnömoniye Eşlik Eden \\ Ülseratif Stomatit ve Vezikülobüllöz Lezyonlar
}

\author{
Ayșe Büyükcam ${ }^{1}$ \\ ' Department of Pediatrics, Hacettepe University School of Medicine, Ankara, Turkey
}

Cite this article as: Büyükcam A. Community-acquired pneumonia associated with ulcerative stomatitis and vesiculobullous lesions. J Pediatr Inf 2018;12(3):e126-e127

A previously healthy 7-year-old girl was consulted to our hospital with fever and very painful bullous on her skin, target lesions and oral mucosal ulcerations. According to the story of the patient, it was learned that she consulted a different hospital due to fever and sore throat 10 days ago and she was prescribed amoxicillin-clavulanate initially, but after four days her fever continued, she started to cough, vesicular lesions around his mouth and ulceration in the oral mucosa were observed. At her admission to our hospital, body temperature was $38.2^{\circ} \mathrm{C}$; respiratory rate was $32 / \mathrm{min}$; pulse rate was $136 / \mathrm{min}$; and blood pressure was 100/60 $\mathrm{mmHg}$. Physical examination revealed red and swollen lips, ulcerative lesions in the mouth, painful bullous and target lesions on the skin and unilateral crepital rales on the left side of the lung (Figure 1). According to the complete blood count from laboratory findings, haemoglobin was $11.8 \mathrm{~g} / \mathrm{dL}$, leukocyte count was $10.100 / \mathrm{mm}^{3}$ (54\% neutrophils, $30 \%$ lymphocytes, $16 \%$ monocytes) and platelet count was $387.000 / \mathrm{mm}^{3}$. Liver function tests, renal function tests and complete urinalysis were normal. Sedimentation rate was 51 $\mathrm{mm} / \mathrm{h}, \mathrm{C}$-reactive protein (CRP) was $7 \mathrm{mg} / \mathrm{dL}$ (normal: 0-0.8 mg/ $\mathrm{dL}$ ). Chest radiography revealed diffuse interstitial infiltrates in the left lung on chest radiograph (Figure 2). The patient was diagnosed with pneumonia and intravenous ceftriaxone (100 $\mathrm{mg} / \mathrm{kg} /$ day $2 \mathrm{x}$ ) was started to patient. On the $4^{\text {th }}$ day of treatment, the patient's ceftriaxone treatment was stopped due to

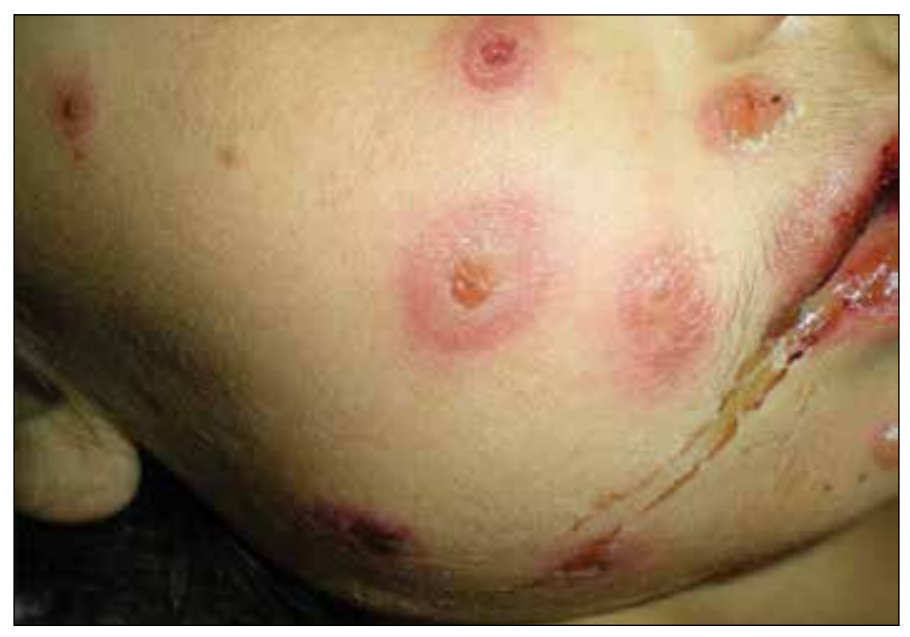

Figure 1. Maculopapular, bullous and target lesions on face.

worsening of the oral mucosal ulcers and new erythematous and target lesions on the face, upper body and extremities. Also Mycoplasma pneumoniae lgM was $6.8 \mathrm{RU} / \mathrm{mL}(0.1-1.1)$ and IgG was negative, and therefore, oral clarithromycin (15 mg/ $\mathrm{kg} /$ day $2 \mathrm{x}$ ) was started.

\section{What is your diagnosis?}

Evaluating the patient's current clinic, she was diagnosed with Stevens-Johnson syndrome (SJS) secondary to M. pneumoniae infection and she received intravenous immunoglobulin 


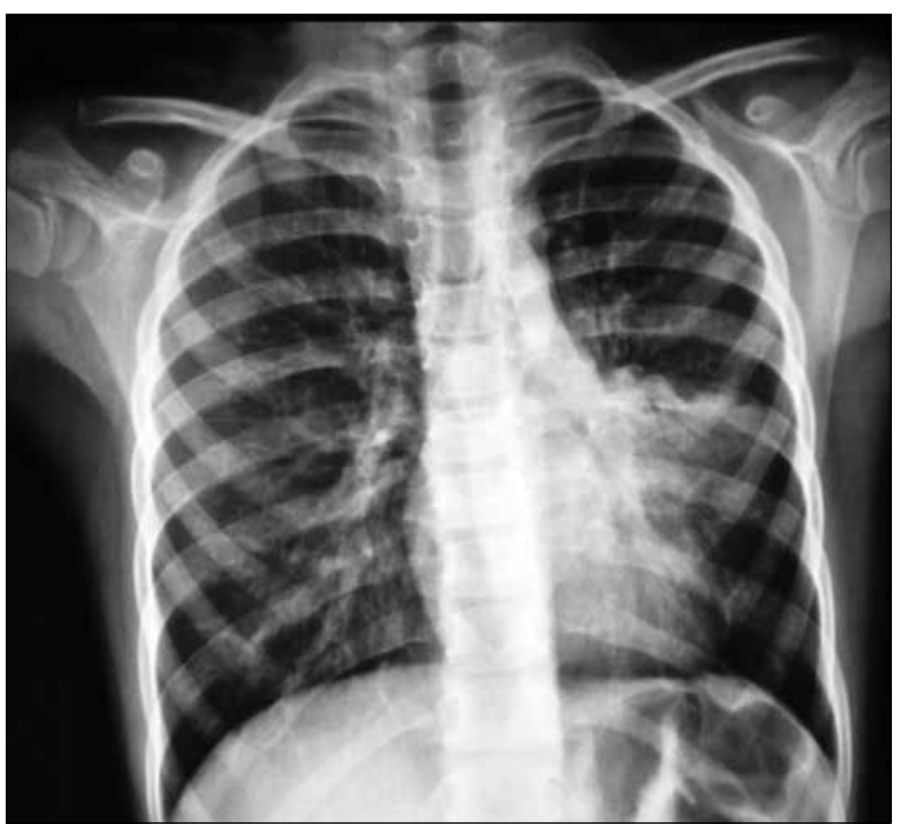

Figure 2. Diffuse interstitial infiltrations in the left lung on chest radiography.

( $400 \mathrm{mg} / \mathrm{kg} /$ dose/day) treatment during 3 days for SJS. In addition, supportive care was applied for oral and skin lesions. The patient's fever decreased 1 day after IVIG treatment. After eight days of treatment, the patient's mucocutaneous lesions and pneumonia findings improved and the patient was discharged. M. pneumoniae lgM was $3.81 \mathrm{RU} / \mathrm{mL}(0-1.1)$ and lg G was $>200$ $\mathrm{RU} / \mathrm{mL}$, tested 3 weeks after the discharge.

M. pneumoniae is one of the reasons for community-acquired pneumonia in children. The most common symptoms and findings include sore throat, hoarseness, fever, cough, headache, tremors, runny nose, myalgia, general weakness, cervical adenopathy and myringitis. Also in some M. pneumoniae infections, dermatological, neurological, renal, cardiac, haematological and hepatic or pancreatic complications can be seen. Dermatological complications include erythematous, maculopapular, vesicular rash and SJS with conjunctivitis, ulcerative stomatitis, and atypical target lesions. In addition, M. pneumoniae is the most common infectious cause of SJS in children. SJS is characterized with severe inflammation, particularly accompanied by acute fever, and necrosis of two or more mucous membranes and systemic symptoms. SJS was first described by Stevens and Johnson in 1922. SJS and toxic epidermal necrolysis (TEN) are serious different forms of the same disease. The incidence of SJS is estimated to be between 1.1 and 7.1/1.000.000 cases per year. The disease is accompanied by skin detachment and mucositis. SJS is mostly associated with drug reactions and less frequently infections. Among infections, M. pneumoniae is the most common pathogen responsible for SJS with various skin lesions. These lesions may be maculopapular and some- times vesiculobullous lesions, and target-like lesions are present in approximately $50 \%$ of patients. Laboratory findings are not diagnostic for SJS. Increase may be observed in Leucocytosis, ESH and transaminases. Treatment options are available for SJS, including corticosteroid therapy, intravenous immunoglobulin (IVIG), cyclosporine and cyclophosphamide. The use of corticosteroids in the treatment of SJS is controversial. There are super-infections and complications risks in corticosteroid treatment. IVIG is another treatment option for SJS. It has been reported that hospitalization is shorter in SJS patients treated with IVIG. IVIG appears to be a useful and safe treatment for children with SJS, and its doses of $0.5-1.0 \mathrm{~g} / \mathrm{kg}$ IVIG for 3 days have been reported to be more effective.

In children with M. pneumoniae infection, if there are atypical skin lesions accompanied by mucosal and bullous and target lesions, SJS should be considered among the diagnoses.

\section{References}

1. Bullen LK, Zenel JA. Visual diagnosis: A 15-year-old female who has cough, rash, and painful swallow. Pediatr Rev 2005;26:176-81.

2. Bystryn JC. Erythema multiforme with mucous membrane involvement and stevens-johnson syndrome are clinically different disorders. Arch Dermatol 1996;132:711-2.

3. Leaute-Labreze C, Lamireau T, Chawki D, Maleville J, Taieb A. Diagnosis, classification, and management of erythema multiforme and stevensjohnson syndrome. Arch Dis Child 2000;83:347-52.

4. Letko E, Papaliodis DN, Papaliodis GN, Daoud YJ, Ahmed AR, Foster CS. Stevens-johnson syndrome and toxic epidermal necrolysis: A review of the literature. Ann Allergy Asthma Immunol 2005;94:419-36; quiz 436-418, 456.

5. Metry DW, Jung P, Levy ML. Use of intravenous immunoglobulin in children with stevens-johnson syndrome and toxic epidermal necrolysis: Seven cases and review of the literature. Pediatrics 2003;112:1430-6.

6. Morici MV, Galen WK, Shetty AK, Lebouef RP, Gouri TP, Cowan GS, et al. Intravenous immunoglobulin therapy for children with stevens-johnson syndrome. J Rheumatol 2000;27:2494-7.

7. Patterson R, Grammer LC, Greenberger PA, Lawrence ID, Zeiss CR, Detjen $P F$, et al. Stevens-johnson syndrome (SJS): Effectiveness of corticosteroids in management and recurrent sjs. Allergy Proc 1992;13:89-95.

8. Rabelink NM, Brakman M, Maartense E, Bril H, Bakker-Wensveen CA, BavinckJN. [erythema multiforme vs. Stevens-johnson syndrome and toxic epidermal necrolysis: An important diagnostic distinction]. Ned Tijdschr Geneeskd 2003;147:2089-94.

9. Tay YK, Huff JC, Weston WL. Mycoplasma pneumoniae infection is associated with stevens-johnson syndrome, not erythema multiforme (von hebra). J Am Acad Dermatol 1996;35:757-60.

10. Weiner LB, MCMillan JA. Mycoplasma pneumonia. In: Long SS, Pickering LK, Prober CG (eds). Principles and practice of pediatric infectious diseases. 2nd ed. New York: Churchill Livingstone, 2003;1005-10. 